University of Wollongong

Research Online

Faculty of Engineering and Information

Faculty of Engineering and Information

Sciences - Papers: Part A

Sciences

$1-1-2014$

Numerical modeling of size effect in micro hydromechanical deep drawing

Hideki Sato

Tokyo Metropolitan University

Ken-ichi Manabe

Tokyo Metropolitan University

Dongbin Wei

University of Wollongong, dwei@uow.edu.au

Zhengyi Jiang

University of Wollongong, jiang@uow.edu.au

Follow this and additional works at: https://ro.uow.edu.au/eispapers

Part of the Engineering Commons, and the Science and Technology Studies Commons

Research Online is the open access institutional repository for the University of Wollongong. For further information contact the UOW Library: research-pubs@uow.edu.au 


\title{
Numerical modeling of size effect in micro hydromechanical deep drawing
}

\begin{abstract}
A modeling of tribological size effects in micro deep drawing (MDD) and micro hydromechanical deep drawing (MHDD) is a main focus in this study. The inner and outer pockets in which the different friction coefficients can be applied at different lubrication conditions are considered on the blank surface. The ratio of the area of outer pockets to inner pockets is changed with the decrease in the size. The low friction coefficient at the outer pockets is assumed in MHDD by considering the lubrication effect of fluid medium. The numerical analysis is performed under six lubrication conditions. The analytical results of punch force-stroke curves are in good agreement with the experimental values. The friction force decreases in MHDD with the decrease in the size although it increases in MDD. The friction coefficient at die shoulder significantly influences the friction force due to high contact pressure in MHDD.
\end{abstract}

\section{Keywords}

hydromechanical, drawing, micro, deep, effect, size, modeling, numerical

\section{Disciplines}

Engineering | Science and Technology Studies

\section{Publication Details}

H. Sato, K. Manabe, D. Wei \& Z. Jiang, "Numerical modeling of size effect in micro hydromechanical deep drawing," in AIP Conference Proceedings (1567): The 9th International Conference and Workshop on Numerical Simulation of 3D Sheet Metal Forming Processes, 2014, pp. 926-929. 


\title{
Numerical Modeling of Size Effect in Micro Hydromechanical Deep Drawing
}

\author{
Hideki Sato ${ }^{a}$ Ken-ichi Manabe ${ }^{b}$, Dongbin Weic and Zhengyi Jiang ${ }^{\mathrm{d}}$ \\ "Department of Mechanical Engineering, Tokyo Metropolitan University, 1-1 Minamiosawa Hachioji-shi, Tokvo, \\ 192-0397, Japan, sato-hideki@ed.tmi.ac.jp \\ ${ }^{3}$ Department of Mechanical Engineering, Tokyo Metropolitan University, 1-1 Minamiosawa Hachioji-shi, Tokvo, \\ 192-0397, Japan,manabe@tmu,ac.jp \\ 'School of Electrical, Mechanical and Mechatronic Systems. University of Technology, Sydney New South Wates, \\ 2007, Australia, dongbin.wei@uts.edu.au \\ "School of Mechanical, Material and Mechatronic Engineering, University of Wollongong NSW, 2522, Australia, \\ jang@uow.edu.cu
}

\begin{abstract}
A modeling of tribological size effects in micro deep drawing (MDD) and micro hydromechanical deep drawing (MHDD) is a main focus in this study. The inner and outer pockets in which the different friction coefficients can be applied at different lubrication conditions are considered on the blank surface. The ratio of the area of outer pockets to imer pockets is changed with the decrease in the size. The low friction coefficient at the outer pockets is assumed in MHDD by considering the lubrication effect of fluid medium. The mumerical analysis is performed under six lubrication condtions. The analytical results of punch fore-stroke curves are in good agreement with the experimental values. The friction force decreases in MHDD with the decrease in the size although it increases in MDD. The friction coefficient at die shoulder significantly infuences the friction force due to high contact pressure in MHDD.
\end{abstract}

Keywords: Modeling, Micro forming, Size effect, Tribology, Micro hydromechanical deep drawing, Fluid pressure. PACS: $46.55 .+\mathrm{d}$

\section{INTRODUCTION}

With the increase of miniaturization in products, a market demand on micro parts is significantly growing. These micro parts need further miniaturization, high accuracy and high functionality to develop the communications, electronic and medical products. However, the knowledge in macro foming cannot be simply scaled down to micro scale because the size effects occur with the decrease in the size [1]. In particular, the tribological size effect causes the low formability in micro forming due to the increase of friction force with the decrease in the size [2].

On the other hand, the hydroforming is widely used in macro scale due to several advantages, such as improvement of forming limit, improvement of shape acouracy and manufacture of complex shape. In particular, the hydrodynamic lubrication which can significantly improve the lubrication occurs in hydromechanical deep drawing [3]. From these backgrounds, a micro hydromechanical deep drawing (MHDD) is developed by the authors to improve the formability in micro forming [4]. It has been clarified that the tribological property can be improved by applying the fluid pressure in MHDD [5]. However, the mechanism of tribological property in MHDD has not been confirmed. In this study, the modeling methods of tribological size effect in micro deep drawing (MDD) and MHDD are developed, and the tribological size effects in MDD and MHDD are confirmed using the developed finite element (FE) model.

\section{FE ANALYSIS}

\section{Modeling of Size Effect in MHDD}

The tribological size effect is mainly caused by the outer pockets that contact with the edge of the blank. The onter pockets cannot keep the lubricant in MDD as shown in Fig. 1 . Furthermore, the ratio of area of outer pockets to inner pockets increases with the decrease in the size to micro scale because the widh of outer pockets $w$ does not change [6]. These cause the tribological size effect in MDD. On the other hand, if the fluid medium is provided to the outer pockets in MHDD as shown in Fig. 1, the lubricant can be kept at the outer pockets. Based on this, it was 
assumed that the outer pockets have a low friction coefficient in MHDD. To model these tribological size effects, the blank surface was divided to imer and outer pockets areas and the different friction coefficients were applied at each pocket. The ratio of outer pockets was expressed by the scale factor $\lambda=D_{0} / 2 w$.

\section{FE model}

The analysis was carried out with an explicit dynamic finite element code. LS-DYNA. The dimension of tools is shown in Fig. 2. The stainless steel (SUS304-H) foil with thickness of $50 \mu \mathrm{m}$ was used The mechanical properties of material used are shown in Table 1 . The isotropic elastoplastic and rigid body were used for the blank and tools, respectively. Fluid pressure was set up to $P=10$ and 30MPa in MHDD. The six kinds of lubrication conditions were used in the analysis as shown in Table 2 . The static and kinetic friction coefficients between the blank and punch were $\mu_{\mathrm{s}}=0.35$ and $\mu_{\mathrm{d}}=0.30$ at all analytical condition, respectively. In MDD, the dry friction and lubrication conditions were adopted. In MHDD, no leakage, leakage between the blank and die, radial pressure without leakage and perfect lubrication conditions were adopted. To evaluate the friction force in MHDD process, the measured punch force $P_{\mathrm{H}}$ is recalculated by the effective punch force $P_{\mathrm{E}}$. It is expressed by

$$
P_{\mathrm{E}}=P_{\mathrm{H}}-F_{\mathrm{H}}=F_{\mathrm{S}}+F_{\mathrm{B}}+F_{\mathrm{F}}
$$

where $F_{\mathrm{Z}}$ is the force to push the punch by fluid pressure, $F_{\mathrm{S}}$ is the pure drawing force, $F_{\mathrm{B}}$ is the bending force and $F_{\mathrm{F}}$ is the friction force at flange and die shoulder area. $F_{\mathrm{S}}$ and $F_{\mathrm{B}}$ are approximately constant in the same dimension of tools. Therefore, the effective punch force $P_{\mathrm{E}}$ can evaluate the difference of friction forces $F_{\mathrm{F}}$ in each condition.

\section{WXPERMENTAL}

In order to verify the validity of FE analysis results, the experiments of MDD and MHDD were performed. $A$ MHDD apparatus which can perform the pressure generation, blanking, drawing and knockout process in the same axis was used to improve the handling. A miniature load cell with rating capacity of $20 \mathrm{KN}$ was used in the tool.
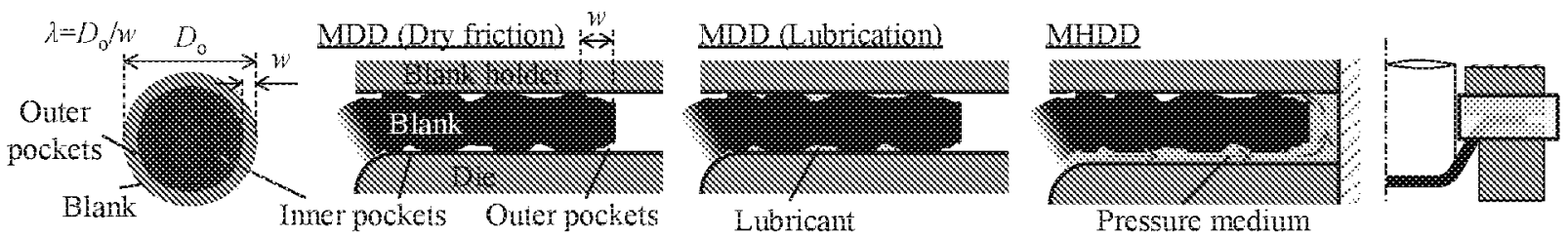

FIGURE 1. Different lubrication conditions at imer and outer pockets between MDD and MHDD.



TABEE 1. Mechanical properties of material used

\begin{tabular}{cccc}
\hline Yield stress, & Young's modulus, & Tensile strength, & Elongation, \\
$\sigma_{y}[\mathrm{MPa}]$ & $E[\mathrm{GPa}]$ & $\sigma_{\mathrm{B}}[\mathrm{MPa}]$ & $\delta \%$ \\
\hline 1217 & 192 & 1334 & 2.4 \\
\hline
\end{tabular}

FIGURE 2. Dimension of tools

TABLE 2. Friction coefficients between blank and BH and die at each lubrication condition.

\begin{tabular}{ccc}
\hline Lubrication conditions & Inner pockets & Outer pockets \\
\hline (A) MDD with dry friction & $\mu_{\mathrm{s}}=0.35, \mu_{\mathrm{d}}=0.30$ & $\mu_{\mathrm{s}}=0.35, \mu_{\mathrm{d}}=0.30$ \\
(B) MDD with lubrication & $\mu_{\mathrm{s}}=0.05, \mu_{\mathrm{d}}=0.03$ & $\mu_{\mathrm{s}}=0.35, \mu_{\mathrm{d}}=0.30$ \\
(C) MHDD with no leakage (Blank-Side wall of die) & $\mu_{\mathrm{s}}=0.05, \mu_{\mathrm{d}}=0.03$ & $\mu_{\mathrm{s}}=0.05, \mu_{\mathrm{d}}=0.03$ \\
(C) MHDD with no leakage (Blank-BH, flange of die) & $\mu_{\mathrm{s}}=0.35, \mu_{\mathrm{d}}=0.30$ & $\mu_{\mathrm{s}}=0.35, \mu_{\mathrm{d}}=0.30$ \\
(D) MHDD with leakage (Blank-Die) & $\mu_{\mathrm{s}}=0.05, \mu_{\mathrm{d}}=0.03$ & $\mu_{\mathrm{s}}=0.05, \mu_{\mathrm{d}}=0.03$ \\
(D) MHDD with leakage (Blank-BH) & $\mu_{\mathrm{s}}=0.35, \mu_{\mathrm{d}}=0.30$ & $\mu_{\mathrm{s}}=0.05, \mu_{\mathrm{d}}=0.03$ \\
(E) MHDD with radial pressure & $\mu_{\mathrm{s}}=0.35, \mu_{\mathrm{d}}=0.30$ & $\mu_{\mathrm{s}}=0.05, \mu_{\mathrm{d}}=0.03$ \\
(F) MHDD with perfect lubrication & $\mu_{\mathrm{s}}=0, \mu_{\mathrm{d}}=0$ & $\mu_{\mathrm{s}}=0, \mu_{\mathrm{d}}=0$ \\
\hline
\end{tabular}


A pump which can provide a maximum pressure value of $20 \mathrm{MPa}$ was used in a hydraulic system. The dimension of tools used and material used in MDD and MHDD are the same as the FE analysis. The experiments of MDD were conducted under dry friction. The machine oil with the kinematic viscosity of $44 \mathrm{~mm}^{2} / \mathrm{s}$ at $40^{\circ} \mathrm{C}$ was used for experiments of MHDD. The drawing speed was $0.4 \mathrm{~mm} / \mathrm{s}$.

\section{RESURTS AND DESCUSON}

Fig. 3 shows the comparison of normalized punch force-stroke curve between experiment and analysis. The punch force-stroke curves obtained by experiment in MDD and MHDD are in good agreement with the analytical results of MDD with dry friction and MHDD with no leakage. However, the punch force-stroke curves between the MDD and MHDD are almost the same. The difference of effective punch force shows the difference of friction force. It means there is a high friction force in the experiment of MHDD due to no leakage of the fluid medium between the blank and die. Generally, the leakage makes the friction force low at die shoulder and flange area. However, the contact pressure between the blank and die becomes high at the die shoulder area due to small $D_{\mathrm{p}} / t$ in MHDD [7]. This prevented the leakage and caused the high friction force in MHDD.

Fig. 4 shows the effects of scale factor on the normalized punch force-stroke curves at MDD with lubrication and MHDD with radial pressure. The shape of punch force-stroke curves in $\lambda=1,2$ is as similar as that with $\lambda=50$ at MDD and MHDD. In these conditions, only the inner or outer pockets exist in the flange area. Therefore, the friction coefficient in the flange area is almost uniform. On the other hand, in $\lambda=5$, the inner and outer pockets are mixed in the flange area. In the initial process, the inner pockets mainly exist at die shoulder and flange area and affect the tribological behavior significantly. Therefore, the punch force-stroke curves are as similar with that in macro scale. However, in the middle process, the ratio of outer pockets increases. Therefore the tribological behavior shifts to that in micro scale. This behavior appears at both MDD and MHDD. This causes the maximum punch force shifts as shown in Fig. 4 (a). These results indicate the ratio of the outer pockets to the flange area during the forming process influences the tribological behavior.

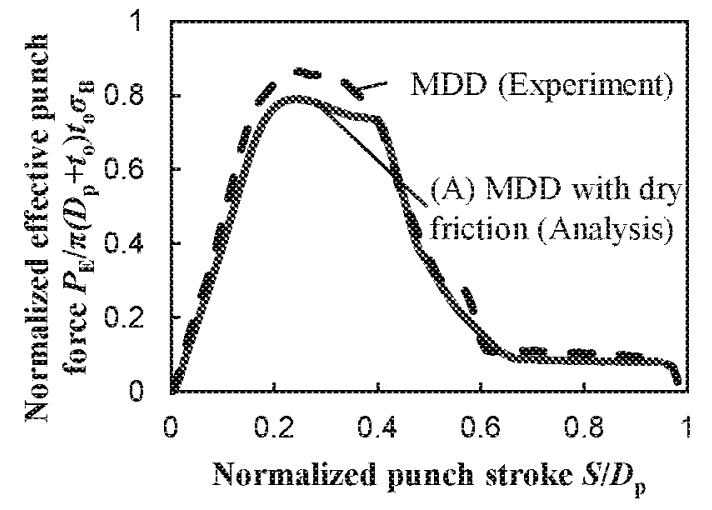

(a) MDD with dry friction

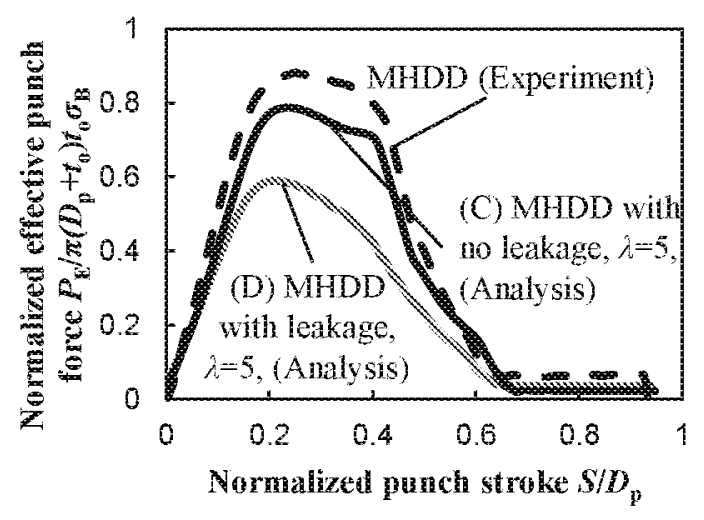

(b) $\mathrm{MHDD}, P=10 \mathrm{MPa}$

FIGURE 3. Comparison of nomalized punch force-siroke curves between experiment and analy sis.

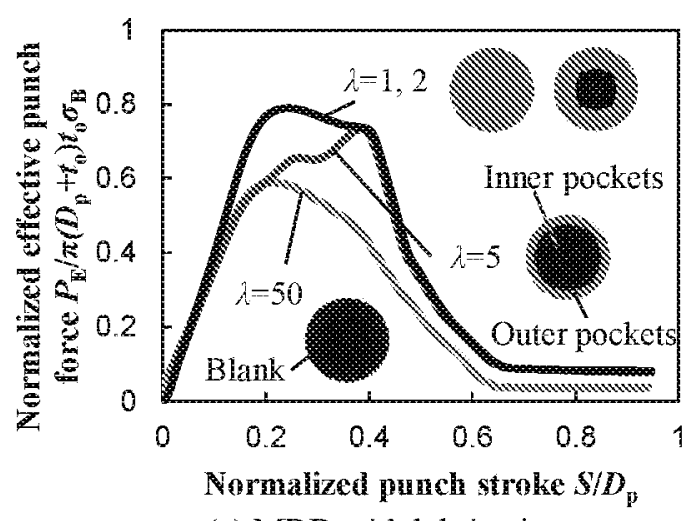

(a) MDD with lubrication

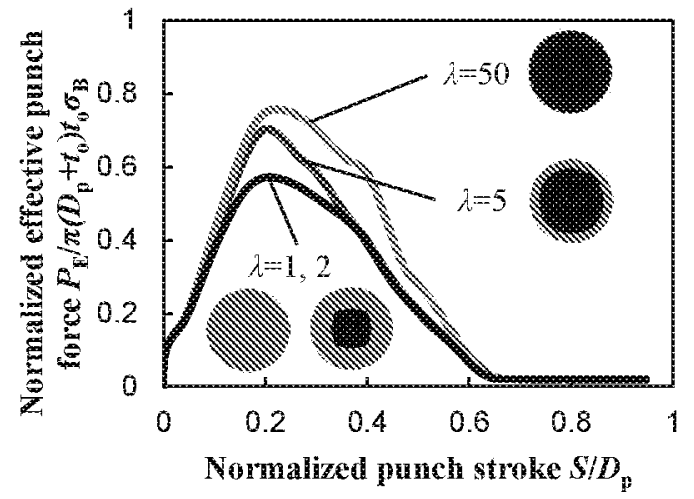

(b) MHDD with radial pressure, $P=30 \mathrm{MPa}$

Figuke 4, Effects of scale factor on nomalized punch force-stroke curve at different lubrication conditionss. 


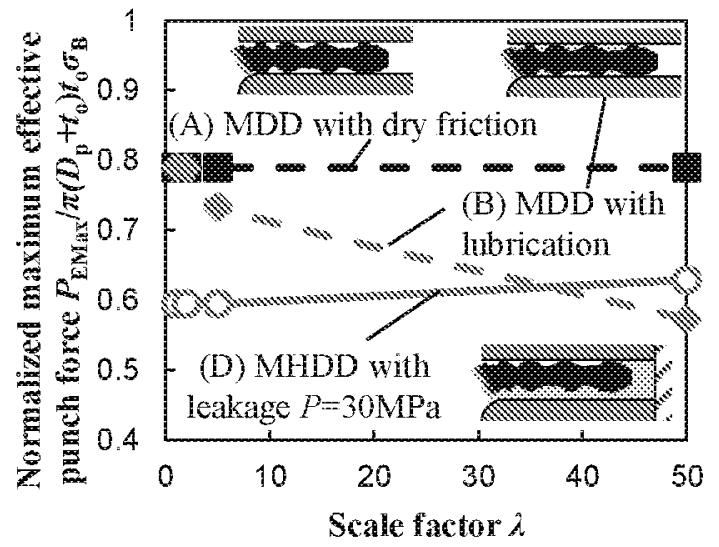

(a) Comparison of MDD and MHDD

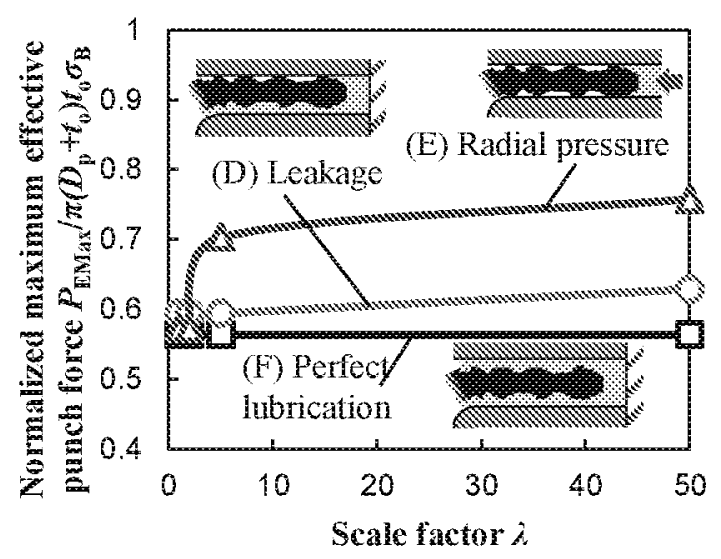

(b) Comparison of lubricate types in MHDD

TGURE 5. Tribological size effects at different lubrication conditions in MDD and MHDD.

Fig. 5 (a) shows the tribological size effects in MDD and MHDD. With the decrease in the size, the friction force increases in case of MDD with lubrication because the ratio of outer pockets increase. When $\lambda=1,2$, the maximum effective punch forces in MDD with the dry friction and lubrication become the same because only the outer pockets exist at flange area. On the other hand, with the decrease in the size, the friction force in MHDD decreases. It can be seen the tribological size effect in MHDD has an opposite behavior with MDD. In MHDD, the fluid medium is provided to the outer pockets whose ratio is high in micro scale. This caused the decrease in friction force in MHDD. This effect has been theoretically confirmed [7]. Fig. 5 (b) shows the effect of the lubrication type on friction force in MHDD. The decrease of friction force in radial pressure condition is much larger than that in leakage condition. Also in radial pressure condition, the friction force significant decreases from $\lambda=5$ to 1 . It is because the contact pressure between the blank and die at die shoulder is higher than that between the blank and blank holder in the small $D_{\mathrm{p}} i t$. Therefore, it can be seen that the decrease in friction coefficient at die shoulder is especially important to decrease the friction force in MHDD. According to the above results, the friction force can decrease with the decrease in size in MHDD, while it only increases in MDD. The friction force can be reduced by filling the fluid medium in the outer pockets in MHDD.

\section{CONCLUSION}

To model the tribological size effect in MDD and MHDD, the inner and outer pockets which have different friction coefficients are considered on the blank surface in FE model. Also, the low friction coefficient at the outer pockets is assumed in MHDD to consider the lubrication effect of fluid medium. The analytical results of punch force-stroke curves are in good agreement with the experimental results. The ratio of outer pockets to the flange area during forming process influences the tribological behavior. With the decrease in the size, the friction force can be reduced in MHDD because of the existence of fluid medium in outer pockets.

\section{REFERENCES}

1. M. Geiger, M. Kleiner, R. Eckstein, N. Tissler, U. Engel, Microforming, CIRP Annals - Manufacturing highlights, 50 , (2001), pp. 445-462.

2. K. V. Putten, M. Framke, G. Hirt, Size Effect on Friction and Yielding in Wire Flat Rolling, Proceedings of the $2^{\text {nd }}$ International of Conference on New Forming Technology, (2007), pp. 583-592.

3. S. H. Zhang, J. Danckert, Development of Hydro-Mechanical Deep Drawing, Jounal of Materials Processing Technology, 83 , (1998), pp. 14-25.

4. K. Manabe, H. Sato, T. Furushima, D. Wei, N. Mathew, Z. Jiang, Deformation Behavior in Micro Sheet Hydroforming Process, Steel Research International, Special edition, (2012), pp. 651-654.

5. H. Sato, K, Manabe, D. Wei, Z. Jiang, Effect of Flud Pressure in Micro Hydromechancal Deep Drawing, Proceedings of the $6^{\text {th }}$ International Conference on Tube Hydroforming, (2013), pp. 313-317.

6. W. L. Chan, M. W. Fu, J. Lu, The Size Effect on Micro Deformation Behavior in Micro-Scale Plastic Deformation, Materials and Design, 32, (2011), pp. 198-206.

7. Y. Sato, K, Manabe, D. Wei, Z. Jiang, Analysis of Axisymmetric Cup Fotming of Metal Foil and Micro Hydroforming Process, Procecdings of the ASME 2013 Intemational Mechanical Engineering Congress \& Exposition, (2013), In press. 